\title{
Variation of prey responses to cues from a mesopredator and an apex predator
}

\author{
TEIGAN CREMONA, ${ }^{1 \star}$ MATHEW S. CROWTHER ${ }^{2}$ AND JONATHAN K. WEBB ${ }^{1}$ \\ ${ }^{1}$ School of the Environment, University of Technology Sydney, PO Box 123, Broadway, NSW 2007, \\ Australia (Email: teigan.cremona@student.uts.edu.au) and ${ }^{2}$ School of Biological Sciences, University of \\ Sydney, Sydney, New South Wales, Australia
}

\begin{abstract}
Detection and avoidance of predator cues can be costly, so it is important for prey to balance the benefits of gaining food against the costs of avoiding predators. Balancing these factors becomes more complicated when prey are threatened by more than one type of predator. Hence, the ability to recognize species-specific predator odours and prioritize behaviours according to the level of risk is essential for survival. We investigated how rock rats, Zyzomys spp. modify their foraging behaviour and giving-up density (GUD) in the presence of an apex predator, the dingo Canis dingo, a mesopredator, the northern quoll Dasyurus hallucatus, a herbivore, the rock wallaby Petrogale brachyotis as a pungency control and water as a procedural control. Both dingoes and quolls consume rock rats, but because quolls can enter small crevices inhabited by rock rats, they pose a greater threat to rock rats than dingoes. Rock rats demonstrated a stronger avoidance to quoll odour than dingo odour, and no avoidance of the pungency control (rock wallaby) and the procedural control (water). GUD values declined significantly over the duration of the study, but did not differ between odour treatments. Our results support the hypothesis that prey vary behaviour according to perceived predator threat, and show stronger responses to potentially more dangerous predators.
\end{abstract}

Key words: dingo, giving-up density, northern quoll, predation risk, predator odours, Zyzomys argurus, Zyzomys maini.

\section{INTRODUCTION}

Predation is a powerful selective force that shapes the behaviour and morphology of prey species (Hill \& Dunbar 1998; Langerhans \& DeWitt 2004). Many species respond to the odours of their predators (Apfelbach et al. 2005) and modify their behaviours according to the source of the odour (Kats \& Dill 1998). In response to predator odours, mammalian prey typically respond by reducing activity or foraging, and increasing habitat use in areas where predator odours are absent (Brown 1999; Apfelbach et al. 2005; Nersesian et al. 2012). These antipredator behaviour modifications are an important mechanism by which prey species reduce their risk of predation (Lima \& Dill 1990; Caro 2005).

In complex trophic interactions, most prey species are threatened by multiple predators (Sih et al. 1998). Due to the cost of responding to predators, (e.g. loss of foraging or reproductive opportunities), prey should recognize species-specific predator odours and prioritize behaviours according to the level of risk (Helfman 1989; Lima \& Bednekoff 1999). Minimizing

${ }^{\star}$ Corresponding author.

Accepted for publication March 2014.

(C) 2014 The Authors

Austral Ecology (C) 2014 Ecological Society of Australia unnecessary antipredator behaviours by prioritizing threats reduces the costs of such activities. As predicted, many fish species show threat-sensitive responses and match the intensity of their responses to the concentration of predator odours, or show stronger responses to predators that have recently eaten conspecifics (Ferrari et al. 2010). Furthermore, combining chemical and visual cues enhances the detection and prioritization of threats in lizards and newts (Mathis \& Vincent 2000; Amo et al. 2006). However, the responses of terrestrial vertebrates to predator odours are less clear. Some mammals do not respond to predator odours, or fail to discriminate between odours of different predators (Apfelbach et al. 2005). Likewise, some lizards show similar antipredator responses to potentially more dangerous predators (Webb et al. 2009). Hence, the question of whether prey use simple rules to assess predation hazard (Bouskila \& Blumstein 1992) or respond to predator cues in a species specific manner (Orrock et al. 2004) is still unresolved.

Evolutionary history and ecology can influence the ability of naïve prey to assess risk and adopt appropriate behavioural responses (Blumstein 2006). During their lifetime, prey species can learn to recognize and avoid predator odours through experience (Lima \& Dill 1990; Dickman 1992; Hayes et al. 2006). Direct 
encounters with predators can be costly, as they can result in injury or death of prey. Hence prey may opt to avoid predator odours, even if the risk of predation is low (Grostal \& Dicke 1999). Non-lethal effects on prey species may be just as important as lethal interactions on the survival of prey species (Werner \& Peacor 2006). Non-lethal interactions can be costly to prey species because of the conflict between the need for food and safety (Brown \& Kotler 2004). Hence, it is important for prey species to balance the costs associated with avoiding predators against the necessity of foraging.

Giving-up density (GUD) is a measure of the resource density within a patch at which an animal will cease foraging (Verdolin 2006). GUD balances the benefits of gaining food against the metabolic and predation costs of foraging, and the missed opportunity cost of not engaging in other activities (Brown 1988). GUD experiments allow researchers to measure the trade-offs that individual foragers make when balancing the benefits of gaining food against the costs of encountering predators (Sih \& McCarthy 2002; Kovacs et al. 2012). By manipulating chemical cues from predators, we can determine whether prey species modify their foraging activities and habitat use in the presence of predator cues.

In northern Australia, the common rock rat (Zyzomys argurus) and the Arnhem rock rat (Zyzomys maini) inhabit rocky areas dominated by a large apex predator, the dingo (Canis dingo), and a smaller mesopredator, the northern quoll (Dasyurus hallucatus). In savanna woodlands, dingoes prey on large macropods and medium sized mammals, but will also feed on seasonally abundant prey, including magpie geese, and dusky rats (Corbett 1989). By contrast, northern quolls prey on insects, and small lizards, birds, frogs and mammals (Oakwood 1997). Although both predators can prey on rock rats, quolls are a lot closer in body size to rock rats than dingoes and can access a larger proportion of the rock rats' refuge. It is therefore not unexpected that quolls would pose a greater threat to rock rats than dingoes. This system provides an opportunity to investigate whether rock rats prioritize predator avoidance depending on the level of threat posed by different predators.

We used GUD experiments to investigate the responses of rock rats (Zyzomys spp.) to faecal odours from two native predators, the northern quoll (Dasyurus hallucatus) and the dingo (Canis dingo). Specifically, we addressed the following questions: (1) Do rock rats respond to predator faecal odours as an indicator of predator presence? (2) If so, do they respond differently to predator species in a threat-sensitive manner? (3) Do rock rats' behavioural responses to predators change according to temporal variation?

\section{METHODS}

\section{Study site}

We conducted the study in the East Alligator Region of Kakadu National Park, Northern Territory, Australia $\left(12^{\circ} 26^{\prime} \mathrm{S}, 132^{\circ} 57^{\prime} \mathrm{E}\right)$. These habitats are composed of rock escarpments or isolated residual masses that can be more than $100 \mathrm{~m}$ above the surrounding country (Freeland et al. 1988). Greater water availability in these rock escarpments from runoff, water absorption by large rock formations, and the presence of aquifers in rock, results in greater plant species richness and productivity (Freeland et al. 1988). A suite of endemic rock-dwelling species (including the common rock rat) occur on the study site, and take advantage of the high food availability and protection from fire and predators that is afforded in such areas. The study site was chosen because it is one of the few sites in the Northern Territory where northern quolls are still present and dingoes are abundant.

\section{Study species}

The Arnhem rock rat, Zyzomys maini, is a moderately large rat, endemic to the sandstone outliers and escarpment of western Arnhem Land (Woinarski 2006). The rock-rats have fragile tails and fur, and many individuals may have no or greatly reduced tails, presumably as a consequence of predator attack. The Arnhem rock rat is the most common species on the study site.

The common rock rat, Zyzomys argurus, is the smallest of the eight species in the rock rat genus (Bradley et al. 1988) occurring in rocky habitats (e.g. outcrops and scree slopes), extending from the Dampier Archipelago in northern Western Australia, through the tropical zone of the Northern Territory and into tropical Queensland, Australia (Fleming 2008). The diet of the common rock rat consists of a range of seeds and grasses depending on what is seasonally available (Begg \& Dunlop 1985).

Rock rats are a common prey item of the northern quoll (Oakwood 1997). Depending on availability, it is also likely that rock rats are at risk of opportunistic dingo predation (May \& Norton 1996).

\section{Experimental design}

We placed feeding trays at each of six individual rock escarpments, which were located more than $500 \mathrm{~m}$ apart to ensure rock rats would not forage at multiple sites (Begg 1981) and were restricted by the locations of sandstone outliers. At each site, we placed trays so that one side was flush with the rock wall of the escarpment, and the other side was exposed to the surrounding vegetation. We set 16 artificial food patches or 'trays' at each of six sites. Trays were spaced $5 \mathrm{~m}$ apart and each tray was randomly allocated to one of the four treatments; northern quoll (Dasyurus hallucatus) and dingo (Canis dingo) faeces as olfactory cues of predators. Rock wallaby (Petrogale brachyotis) faeces were used as a pungency control, as they are a common herbivore in the area, and 
water as a procedural control. The distance between trays was selected to ensure that rock rats would have access to at least one, of each of the treatments, within the mean distance between trapped individuals (40-44 m; Begg 1981).

Foraging trays consisted of rectangular plastic containers $(17 \times 12 \times 4 \mathrm{~cm})$, with clear plastic lids to prevent birds and other non-target animals from feeding at the stations. Coopex powder (Bayer, Sydney) was dusted around the trays to repel ants and other insects that might otherwise have visited the trays.

We monitored visitations using tracking plates, consisting of a single $8.5 \times 6 \mathrm{~cm}$ sheet of stiff plastic placed at the feeding tray entrance. The sheets were sprayed with a 95:5 solution of methylated spirits: paraffin oil, into which $50 \mathrm{~g}$ of coloured chalk had been dissolved. The methylated spirits evaporated after application, leaving a fine residue of chalk powder that clearly showed any footprints on the plastic sheets. Triggs (2004) was used to identify species from the tracks. It was not possible to distinguish between the two species of rock rats using their tracks alone, therefore, all rat tracks were recorded as Zyzomys spp. If no tracks were present, a non-visitation or avoidance event was recorded and this record was excluded from the GUD analysis. Visitations of different species were recorded as presence/absence only.

We placed 10 slivered almonds in a sawdust matrix in each foraging tray. A pilot study was performed to determine an adequate number of foraging items and appropriate matrix type. We then sprayed a solution of the allocated treatment in a $30 \mathrm{~cm}$ diameter in the area surrounding the foraging tray. Faecal odour solutions were made by diluting $30 \mathrm{~g}$ of crushed fresh faeces (obtained from the Territory Wildlife Park) in $250 \mathrm{~mL}$ of water. Identical solutions were used across all sites. Foraging trays were checked and reset in the early morning for three consecutive nights over three consecutive months (May, June and July 2012) in the early dry season.

\section{Statistical analyses}

We used a two-factor ANOVA on square root transformed GUD data to compare between odour treatments and months. Relative visitation of trays by rock rats was analysed with a chi-squared analysis of a contingency table, comparing visitation to non-visitation of trays relative to each odour treatment. Visitations were low, especially in May, and so data were pooled over months. We then determined whether any differences in the likelihood of rock rats visiting either quoll or dingo odour trays compared with other treatments by subdividing the contingency table (Zar 1999) and testing with chi-squared tests with Yate's corrections for small sample size. We used SPSS v. 20 for all analyses (SPSS, IBM, Armonk, NY, USA).

\section{RESULTS}

There was no significant difference among treatments $\left(F_{3,183}=0.35, P=0.79\right)$ for the GUD values. However, GUD values decreased over the three months of the study $\left(F_{2,183}=61.28, P<0.001\right.$; Fig. 1$)$.

There was heterogeneity of likelihood of rock rats visiting the different odour treatments (Pearson's

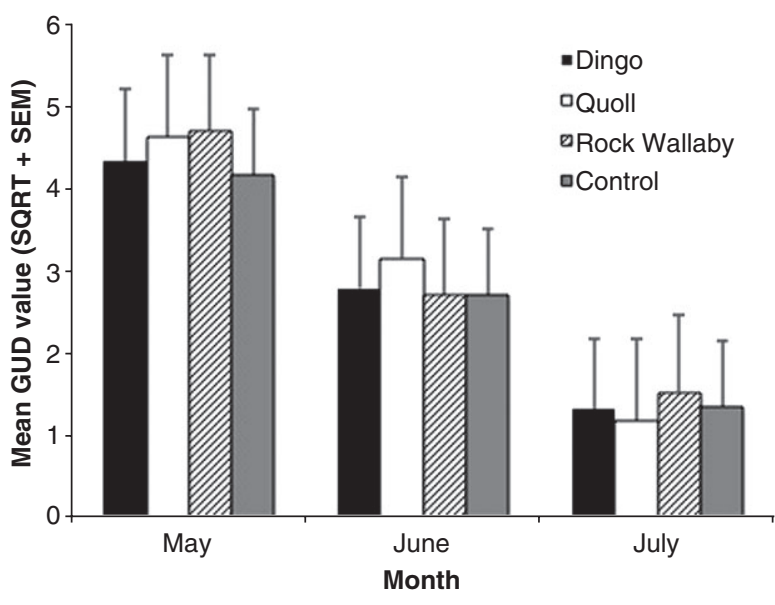

Fig. 1. Mean ( \pm SEM) giving-up density (GUD) values for Zyzomys spp. after foraging at trays bearing dingo, quoll, rock wallaby or control (water) during three consecutive months. Means were square-root (SQRT) transformed.

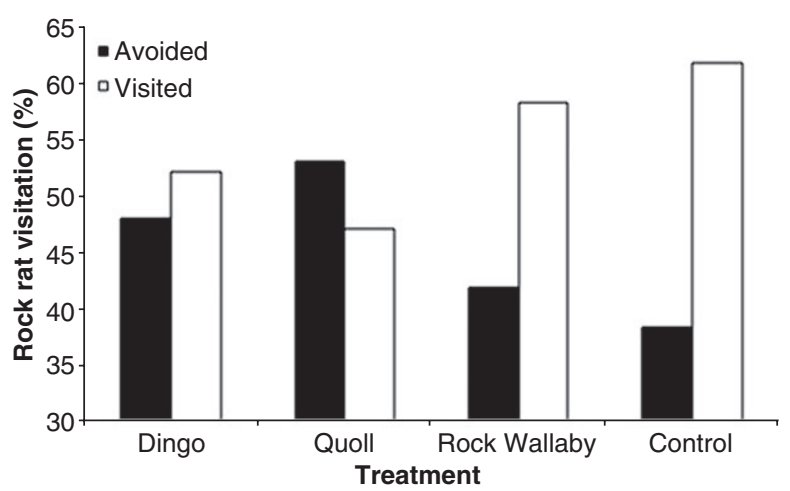

Fig. 2. Percentage of rock rat visitation of foraging trays bearing dingo, quoll, rock wallaby or control (water) during three consecutive months.

$\chi^{2}=8.74$, d.f. $=3, P=0.033$; Fig. 2). Rock rats avoided trays treated with quoll odour, while visiting the other three treatments more often than quoll scented trays $\left(\chi^{2}\right.$ with Yates correction $=5.03$, d.f. $=1$, $P=0.025)$. Rock rats did not avoid trays treated with dingo odour compared with the other treatments $\left(\chi^{2}\right.$ with Yates correction $=0.55$, d.f. $\left.=1, P=0.460\right)$.

\section{DISCUSSION}

Optimal foraging theory predicts that in a high-risk environment, prey species will forage for shorter periods of time (Lima \& Bednekoff 1999). GUD experiments are useful in quantifying the foraging trade-offs that prey make in the presence of predator cues. In the current study, GUDs were not significantly different across treatments, suggesting that when rock rats visited a tray they displayed the same foraging 
behaviour regardless of treatment. While there was no difference in GUD, rock rats were less likely to visit foraging trays scented with quoll faecal odour compared with trays scented with water or herbivore faeces. Although predator faecal odours can be an unreliable indicator of predator presence, and hence predation risk (Banks et al. 2003; Blanchard et al. 2003), many prey species recognize and avoid the faecal odours of their predators (Dickman 1992; Persons et al. 2001; Hayes et al. 2006; Kovacs et al. 2012).

Instead of 'giving up' foraging at predator-scented trays, rock rats avoided these trays by not visiting them at all. This avoidance was strongest for trays scented with quoll faeces, but was also evident for trays scented with dingo faeces. The avoidance of predator-scented areas suggests that rock rats perceived such sites as high-risk, and modified their behaviour by avoiding the predator odour.

The current study used faecal odours from an apex predator, the dingo, and a mesopredator, the northern quoll. Rock rats are potential prey for both of these predators, but rock rats can seek refuge in rocky outcrops which dingoes have limited access to (Trainor et al. 2000). Quolls inhabit these rocky outcrops and scree slopes and can also access some of the crevices used by rock rats (Woinarski et al. 2008) due to their relatively similar body size. Rock rats are more likely to encounter quolls in these areas, it is therefore possible that quolls pose a higher risk than dingoes. The results of the current study provide support for the notion that rats prioritize predator avoidance, and avoid quoll odour more than dingo odour. Dingoes preferentially prey on larger mammals compared with smaller and medium-sized mammals (Letnic et al. 2009b; Cupples et al. 2011). They have also been shown to benefit populations of small and medium-sized mammals through their suppression of mesopredators (Johnson et al. 2007; Johnson \& VanDerWal 2009; Letnic et al. 2009a,b; Wallach et al. 2009; Brook et al. 2012). Hence rock rats may not perceive dingoes as much of a threat as quolls, and rock rat populations could benefit indirectly from their presence. Risk perception in prey species can also be influenced by the diet preferences of the predator. For example, fathead minnows show stronger antipredator responses to specialist piscivores than to the generalists (Ferrari et al. 2007) demonstrating the ability of prey to vary their response using the diet cues of their predators. Neither of the predators in the current system are small mammal specialists, yet the frequency of the prey species inclusion in the predator's diet would provide a risk-indicator to the prey species.

Although rock rats may encounter dingoes infrequently, they still avoided areas scented by this predator. Potentially, rats may detect a common odour present in the faeces of predators, which trigger a generalized avoidance response (Dickman \& Doncaster

doi:10.1111/aec.12138
1984). For example, in Western Australia, introduced house mice avoided traps scented with the faeces of the western quoll, a species that it did not share a long evolutionary history with (Dickman 1992). However, the level of avoidance was weaker than for traps scented with the faeces of the red fox and the feral cat, predators with which house mice have coevolved. The fact that mice responded to quoll odours suggests that prey either respond to common signals in predator faeces, or rapidly learn to avoid novel predator faecal odours (Dickman 1992). For example, herbivores may detect sulphurous metabolites of meat digestion in predator faeces (Fendt et al. 2005). Likewise, the predators diet can also influence prey behaviour (Berton et al. 1998). Many prey species are more likely to avoid the odour of a predator fed a diet of conspecifics when compared with a diet of heterospecifics (Venzon et al. 2000; Chivers et al. 2007; Cox et al. 2010).

We observed a strong effect of time on forage uptake rates in foraging trays, with uptake, and therefore time spent foraging, increasing with each subsequent month. There are two likely explanations for this temporal pattern. The first explanation is that rats habituated to the odours and foraging trays. Habituation to predator odours has been reported in a wide range of species (Verdolin 2006; Ylonen et al. 2006), including Australian rodents (Kovacs et al. 2012). In the laboratory Rattus norvegicus rapidly habituates to cat odour (Dielenberg \& McGregor 1999). Habituation to predator scented foraging trays is therefore possible, but has not been described previously. Recapture of 'trap-happy' individuals often occurs in trapping studies (Phillips \& Winchell 2011), and a similar phenomenon may have occurred in the current study, with rock rats repeatedly visiting trays due to an association of the apparatus with food.

The second potential explanation for the declining GUD over the duration of the study is increasing energy requirements of the prey and limitation of natural resources. However, since the study was performed in the early-mid dry season when food availability for rock rats is at its highest (Begg 1981), this is unlikely.

Since rocky habitats constitute a large proportion of Australian mammals' habitat (Freeland et al. 1988) there must be a significant advantage of sheltering in these areas. Many prey species will take refuge in rock shelters because of the protection it affords from predators. This has been especially evident throughout the current mammal decline in northern Australia (Woinarski et al. 2010). Species such as the northern quoll have declined or become extinct in much of the lowland savanna that they inhabit, while they have persisted in rock escarpments where they can seek refuge from their predators (Woinarski et al. 2008). Some rock-dwelling species do not forage far from the refuge provided by the escarpments (Tuft et al. 2011). Hence, for many prey species, distance from refuges

(C) 2014 The Authors

Austral Ecology (C) 2014 Ecological Society of Australia 
(Apfelbach et al. 2005; Hayes et al. 2006) and other environmental factors such as moonlight and vegetation cover (Orrock et al. 2004) may be a stronger indicator of predation risk than predator odours.

\section{CONCLUSIONS}

By using a GUD approach to quantify prey responses to predator odours, we demonstrated that rock rats avoided foraging trays scented with predator faecal odours. Carefully controlled laboratory studies to quantify the behavioural responses of rock rats to predator odours could clarify whether habituation occurs in this species (Dielenberg \& McGregor 1999). Rock rats demonstrated a stronger avoidance to quoll odour than dingo odour, suggesting that rock rats perceive quolls as more dangerous than dingoes. These results support the hypothesis that prey vary predator avoidance behaviour depending on the level of threat posed by the predator (Helfman 1989). Given a simple trophic cascade with only two native terrestrial mammalian predators, quolls and dingoes, it is not unexpected that prey can identify which predator is more dangerous and respond accordingly (Blumstein 2006). The current study provides support for the theory that small mammals may not be as threatened by dingoes than other predators, and may indirectly benefit through the suppression of mesopredators (Brook et al. 2012).

\section{ACKNOWLEDGEMENTS}

We would like to acknowledge the assistance of the staff at Kakadu National Park, especially Anne O'Dea, Matt Dunn and Greg Sattler. We thank Kakadu's traditional owners for permission to work on their lands, and their interest in the project. We are grateful to Damien Stanioch, Lynda Veyret and the staff at Territory Wildlife Park for providing scats for the study. This study was approved by the University of Sydney Animal Ethics Committee (protocol L04/ 8-2011/3/5594) and by Kakadu National Park (permit RK775). We thank two anonymous reviewers for their comments on the manuscript.

\section{REFERENCES}

Amo L., Lopez P. \& Martin J. (2006) Can wall lizards combine chemical and visual cues to discriminate predatory from non-predatory snakes inside refuges? Ethology 112, 478-84.

Apfelbach R., Blanchard C. D., Blanchard R. J., Hayes R. A. \& McGregor I. S. (2005) The effects of predator odors in mammalian prey species: a review of field and laboratory studies. Neurosci. Biobehav. Rev. 29, 1123-44.

Banks P. B., Hughes N. K. \& Rose T. A. (2003) Do Australian native small mammals avoid faeces of domestic dogs? Aust. Zool. 32, 406-9.
Begg R. J. (1981) The small mammals of little nourlangie rock, NT. 4. Ecology of Zyzomys woodwardi, the large rock-rat, and Zyzomys argurus, the common rock-rat, (rodentia, muridae). Aust. Wildl. Res. 8, 307-20.

Begg R. J. \& Dunlop C. J. (1985) The diets of the large rock-rat, Zyzomys woodwardi, and the common rock-rat, Zyzomys argurus (rodentia, muridae). Aust. Wildl. Res. 12, 19-24.

Berton F., Vogel E. \& Belzung C. (1998) Modulation of mice anxiety in response to cat odor as a consequence of predators diet. Physiol. Behav. 65, 247-54.

Blanchard D. C., Griebel G. \& Blanchard R. J. (2003) Conditioning and residual emotionality effects of predator stimuli: some reflections on stress and emotion. Prog. Neuropsychopharmacol. Biol. Psychiatry 27, 1177-85.

Blumstein D. T. (2006) The multipredator hypothesis and the evolutionary persistence of antipredator behavior. Ethology $112,1-9$.

Bouskila A. \& Blumstein D. T. (1992) Rules of thumb for predation hazard assessment: predictions from a dynamic model. Am. Nat. 139, 161-76.

Bradley A. J., Kemper C. M., Kitchener D. J., Humphreys W. F., How R. A. \& Schmitt L. H. (1988) Population ecology and physiology of the common rock rat, Zyzomys argurus (Rodentia, Muridae) in tropical Northwestern Australia. 7. Mammal. 69, 749-64.

Brook L. A., Johnson C. N. \& Ritchie E. G. (2012) Effects of predator control on behaviour of an apex predator and indirect consequences for mesopredator suppression. $\mathcal{F}$. Appl. Ecol. 49, 1278-86.

Brown J. S. (1988) Patch use as an indicator of habitat preference, predation risk, and competition. Behav. Ecol. Sociobiol. $22,37-47$.

Brown J. S. (1999) Vigilance, patch use and habitat selection: foraging under predation risk. Evol. Ecol. Res. 1, 4971.

Brown J. S. \& Kotler B. P. (2004) Hazardous duty pay and the foraging cost of predation. Ecol. Lett. 7, 999-1014.

Caro T. (2005) Antipredator Defenses in Birds and Mammals. University of Chicago Press, Chicago, IL.

Chivers D. P., Zhao X. \& Ferrari M. C. O. (2007) Linking morphological and behavioural defences: prey fish detect the morphology of conspecifics in the odour signature of their predators. Ethology 113, 733-9.

Corbett L. K. (1989) Assessing the diet of dingoes from feces: a comparison of 3 methods. F. Wildl. Manage. 53, 343-6.

Cox T. E., Murray P. J., Hall G. P. \& Li X. H. (2010) Pest responses to odors from predators fed a diet of target species conspecifics and heterospecifics. F.Wildl. Manage. 74, 1737-44.

Cupples J. B., Crowther M. S., Story G. \& Letnic M. (2011) Dietary overlap and prey selectivity among sympatric carnivores: could dingoes suppress foxes through competition for prey? F. Mammal. 92, 590-600.

Dickman C. R. (1992) Predation and habitat shift in the house mouse, Mus domesticus. Ecology 73, 313-22.

Dickman C. R. \& Doncaster C. P. (1984) Responses of small mammals to red fox (Vulpes vulpes) odour. F. Zool. 204, 521-31.

Dielenberg R. A. \& McGregor I. S. (1999) Habituation of the hiding response to cat odor in rats (Rattus norvegicus). 7. Comp. Psychol. 113, 376-87.

Fendt M., Endres T., Lowry C. A., Apfelbach R. \& McGregor I. S. (2005) TMT-induced autonomic and behavioral changes and the neural basis of its processing. Neurosci. Biobehav. Rev. 29, 1145-56. 
Ferrari M. C. O., Brown M. R., Pollock M. S. \& Chivers D. P. (2007) The paradox of risk assessment: comparing responses of fathead minnows to capture-released and diet-released alarm cues from two different predators. Chemoecology 17, 157-61.

Ferrari M. C. O., Wisendon B. D. \& Chivers D. P. (2010) Chemical ecology of predator-prey interactions in aquatic ecosystems: a review and prospectus. Can. F. Zool./Rev. Can. Zool. 88, 698-724.

Fleming M. R. (2008) Common rock rat, Zyzomys argurus. In: The Mammals of Australia (eds S. Van Dyck \& R. Strahan) pp. 652-4. Reed New Holland, Sydney.

Freeland W. J., Winter J. W. \& Raskin S. (1988) Australian rockmammals - a phenomenon of the seasonally dry tropics. Biotropica 20, 70-9.

Grostal P. \& Dicke M. (1999) Direct and indirect cues of predation risk influence behavior and reproduction of prey: a case for acarine interactions. Behav. Ecol. 10, 422-7.

Hayes R. A., Nahrung H. F. \& Wilson J. C. (2006) The response of native Australian rodents to predator odours varies seasonally: a by-product of life history variation? Anim. Behav. 71, 1307-14.

Helfman G. S. (1989) Threat-sensitive predator avoidance in damsel fish-trumpet fish interactions. Behav. Ecol. Sociobiol. 24, 47-58.

Hill R. A. \& Dunbar R. I. M. (1998) An evaluation of the roles of predation rate and predation risk as selective pressures on primate grouping behaviour. Behaviour 135, 411-30.

Johnson C. N., Isaac J. L. \& Fisher D. O. (2007) Rarity of a top predator triggers continent-wide collapse of mammal prey: dingoes and marsupials in Australia. Proc. R. Soc. Lond. B. Biol Sci 274, 341-6.

Johnson C. N. \& VanDerWal J. (2009) Evidence that dingoes limit abundance of a mesopredator in eastern Australian forests. F. Appl. Ecol. 46, 641-6.

Kats L. B. \& Dill L. M. (1998) The scent of death: chemosensory assessment of predation risk by prey animals. Ecoscience 5, 361-94.

Kovacs E. K., Crowther M. S., Webb J. K. \& Dickman C. R. (2012) Population and behavioural responses of native prey to alien predation. Oecologia $168,947-57$.

Langerhans R. B. \& DeWitt T. J. (2004) Shared and unique features of evolutionary diversification. Am. Nat. 164, 33549.

Letnic M., Crowther M. S. \& Koch F. (2009a) Does a toppredator provide an endangered rodent with refuge from an invasive mesopredator? Anim. Conserv. 12, 302-12.

Letnic M., Koch F., Gordon C., Crowther M. S. \& Dickman C. R. (2009b) Keystone effects of an alien top-predator stem extinctions of native mammals. Proc. R. Soc. Lond. B. Biol Sci 276, 3249-56.

Lima S. \& Bednekoff P. (1999) Temporal variation in danger drives antipredator behavior: the predation risk allocation hypothesis. Am. Nat. 153, 649-59.

Lima S. \& Dill L. (1990) Behavioral decisions made under the risk of predation: a review and prospectus. Can. F. Zool./Rev. Can. Zool. 68, 619-40.

Mathis A. \& Vincent F. (2000) Differential use of visual and chemical cues in predator recognition and threat-sensitive predator-avoidance responses by larval newts (Notophthalmus viridescens). Can. F. Zool. 78, 1646-52.

May S.A. \& Norton T.W. (1996) Influence of fragmentation and disturbance on the potential impact of feral predators on native fauna in Australian forest ecosystems. Wildl. Res. 23, 387-400.
Nersesian C. L., Banks P. B. \& McArthur C. (2012) Behavioural responses to indirect and direct predator cues by a mammalian herbivore, the common brushtail possum. Behav. Ecol. Sociobiol. 66, 47-55.

Oakwood M. (1997) The ecology of the northern quoll, Dasyurus hallucatus. Australian National University, Canberra.

Orrock J. L., Danielson B. J. \& Brinkerhoff R. J. (2004) Rodent foraging is affected by indirect, but not by direct, cues of predation risk. Behav. Ecol. 15, 433-7.

Persons M. H., Walker S. E., Rypstra A. L. \& Marshall S. D. (2001) Wolf spider predator avoidance tactics and survival in the presence of diet-associated predator cues (Araneae: Lycosidae). Anim. Behav. 61, 43-51.

Phillips R. B. \& Winchell C. S. (2011) Reducing nontarget recaptures of an endangered predator using conditioned aversion and reward removal. f. Appl. Ecol. 48, 1501-7.

Sih A., Englund G. \& Wooster D. (1998) Emergent impacts of multiple predators on prey. Trends Ecol. Evol. 13, 350-5.

Sih A. \& McCarthy T. M. (2002) Prey responses to pulses of risk and safety: testing the risk allocation hypothesis. Anim. Behav. 63, 437-43.

Trainor C., Fisher A., Woinarski J. \& Churchill S. (2000) Multiscale patterns of habitat use by the Carpentarian rock-rat (Zyzomys palatalis) and the common rock-rat (Z. argurus). Wildl. Res. 27, 319-32.

Triggs B. (2004) Tracks, Scats and Other Traces: A Field Guide to Australian Mammals. Oxford University Press, Melbourne.

Tuft K. D., Crowther M. S., Connell K., Mueller S. \& McArthur C. (2011) Predation risk and competitive interactions affect foraging of an endangered refuge-dependent herbivore. Anim. Conserv. 14, 447-57.

Venzon M., Janssen A., Pallini A. \& Sabelis M.W. (2000) Diet of a polyphagous arthropod predator affects refuge seeking of its thrips prey. Anim. Behav. 60, 369-75.

Verdolin J. L. (2006) Meta-analysis of foraging and predation risk trade-offs in terrestrial systems. Behav. Ecol. Sociobiol. 60, 457-64.

Wallach A. D., Murray B. R. \& O’Neill A. J. (2009) Can threatened species survive where the top predator is absent? Biol. Conserv. 142, 43-52.

Webb J. K., Du W. G., Pike D. A. \& Shine R. (2009) Chemical cues from both dangerous and nondangerous snakes elicit antipredator behaviours from a nocturnal lizard. Anim. Behav. 77, 1471-8.

Werner E. E. \& Peacor S. D. (2006) Lethal and nonlethal predator effects on an herbivore guild mediated by system productivity. Ecology 87, 347-61.

Woinarski J. (2006) Threatened species of the Northern Territory - Arnhem Rock-rat, Zyzomys maini. Threatened Species Information Sheet. Available from URL: http:// www.lrm.nt.gov.au/

Woinarski J. C. Z., Armstrong M., Brennan K. et al. (2010) Monitoring indicates rapid and severe decline of native small mammals in Kakadu National Park, northern Australia. Wildl. Res. 37, 116-26.

Woinarski J. C. Z., Oakwood M., Winter J. et al. (2008) Surviving the toads: patterns of persistence of the northern quoll Dasyurus hallucatus in Queensland. Report to The Australian Government's Natural Heritage Trust, March 2008.

Ylonen H., Eccard J. A., Jokinen I. \& Sundell J. (2006) Is the antipredatory response in behaviour reflected in stress measured in faecal corticosteroids in a small rodent? Behav. Ecol. Sociobiol. 60, 350-8.

Zar J. H. (1999) Biostatistical Analysis. Prentice-Hall, Upper Saddle River. 